\title{
Impaired resolution of inflammatory response in the lungs of JF1/Msf mice following carbon nanoparticle instillation
}

Koustav Ganguly ${ }^{1,6}$, Swapna Upadhyay ${ }^{1,6}$, Martin Irmler², Shinji Takenaka1, Katrin Pukelsheim¹, Johannes Beckers ${ }^{2,3}$, Martin Hrabé De Angelis ${ }^{2,3}$, Eckard Hamelmann ${ }^{4,5}$, Tobias Stoeger ${ }^{1 * \dagger}$ and Holger Schulz $z^{1,7 \dagger}$

\begin{abstract}
Background: Declined lung function is a risk factor for particulate matter associated respiratory diseases like asthma and chronic obstructive pulmonary disease (COPD). Carbon nanoparticles (CNP) are a prominent component of outdoor air pollution that causes pulmonary toxicity mainly through inflammation. Recently we demonstrated that mice $(\mathrm{C} 3 \mathrm{H} / \mathrm{HeJ})$ with higher than normal pulmonary function resolved the elicited pulmonary inflammation following CNP exposure through activation of defense and homeostasis maintenance pathways. To test whether CNP-induced inflammation is affected by declined lung function, we exposed JF1/Msf (JF1) mice with lower than normal pulmonary function to CNP and studied the pulmonary inflammation and its resolution.

Methods: $5 \mu \mathrm{g}, 20 \mu \mathrm{g}$ and $50 \mu \mathrm{g}$ CNP (Printex 90) were intratracheally instilled in JF1 mice to determine the dose response and the time course of inflammation over 7 days (20 $\mathrm{mg}$ dosage). Inflammation was assessed using histology, bronchoalveolar lavage (BAL) analysis and by a panel of 62 protein markers.

Results: $24 \mathrm{~h}$ after instillation, $20 \mu \mathrm{g}$ and $50 \mu \mathrm{g}$ CNP caused a 25 fold and 19 fold increased polymorphonuclear leucocytes (PMN) respectively while the $5 \mu \mathrm{g}$ represented the 'no observable adverse effect level' as reflected by PMN influx $(9.7 \times 10$ E3 vs $8.9 \times 10$ E3), and BAL/lung concentrations of pro-inflammatory cytokines. Time course assessment of the inflammatory response revealed that compared to day 1 the elevated BAL PMN counts ( $246.4 \times$ 10E3) were significantly decreased at day $3(72.9 \times 10 \mathrm{E} 3)$ and day $7(48.5 \times 10 \mathrm{E} 3)$ but did not reach baseline levels indicating slow PMN resolution kinetics. Strikingly on day 7 the number of macrophages doubled $(455.0 \times 10 \mathrm{E} 3$ vs $204.7 \times 10 \mathrm{E} 3)$ and lymphocytes were 7 -fold induced $(80.6 \times 10 \mathrm{E} 3$ vs $11.2 \times 10 \mathrm{E} 3)$ compared to day 1 . At day 7 elevated levels of IL1B, TNF, IL4, MDC/CCL22, FVII, and VWF were detected in JF1 lungs which can be associated to macrophage and lymphocyte activation.
\end{abstract}

Conclusion: This explorative study indicates that JF1 mice with impaired pulmonary function also exhibits delayed resolution of particle mediated lung inflammation as evident from elevated PMN and accumulation of macrophages and lymphocytes on day7. It is plausible that elevated levels of IL1B, IL4, TNF, CCL22/MDC, FVII and VWF counteract defense and homeostatic pathways thereby driving this phenomenon.

\footnotetext{
* Correspondence: tobias.stoeger@helmholtz-muenchen.de

† Contributed equally

${ }^{1}$ Comprehensive Pneumology Center, Institute of Lung Biology and Disease, Helmholtz Zentrum München, German Research Center for Environmental Health, Neuherberg/Munich, Germany

Full list of author information is available at the end of the article
}

\section{Biomed Central}

(c) 2011 Ganguly et al; licensee BioMed Central Ltd. This is an Open Access article distributed under the terms of the Creative Commons Attribution License (http://creativecommons.org/licenses/by/2.0), which permits unrestricted use, distribution, and reproduction in any medium, provided the original work is properly cited. 


\section{Introduction}

A major component of urban air pollution is particulate matter (PM). Various epidemiological and clinical studies have shown the correlation between ambient PM concentration and adverse respiratory health effects throughout the developing countries and the industrialized world. Exposure to PM has been associated with an increased risk of various respiratory and cardiopulmonary diseases, increased mortality, and emergency room visits due to respiratory problems and restricted lung function [1-3]. Interestingly, several studies show that individuals with poor pulmonary function are expected to be at higher risk to respiratory diseases [4-6] like asthma or chronic obstructive pulmonary disease (COPD). Carbon black is an ingredient in rubber, plastics, inks and paints with an annual production of 10 million tons [7] indicating its wide usage and potentially massive exposure in day to day life among people of various working class. Carbon nanoparticles (CNP) also constitutes the core of combustion derived particles [8] and represents relevant surrogates for exhaust particles from modern diesel engines $[9,10]$.

Inflammatory responses, triggered by pro-oxidative particle properties, are considered to attribute significantly to chronic pulmonary disease processes, such as COPD. Beside exposure to cigarette smoke, traffic and domestic heating as well as indoor house cooking are major sources of local combustion related particle exposures [11,12]. In this context ultrafine carbon particles are an important component of air pollution with respect to particle number and surface area. An increasing use of engineered nanoparticles in all spheres of life makes CNP also an evolving source of human exposure [13]. CNPs regardless of their different sources exhibit properties not displayed by their macroscopic counterparts. The high pulmonary deposition efficiency along with their large specific surface area, ready to interact with biological material and their potential to evade lung clearance by entering pulmonary cells is considered to be important in driving the emerging health effects of CNP linked to respiratory toxicity $[14,15]$.

Previously $\mathrm{C} 3 \mathrm{H} / \mathrm{HeJ}$ (C3) and JF1/Msf (JF1) were detected to be the most divergent inbred mouse strains based on a pulmonary function screen [16-18]. For example, JF1 mice have smaller and less compliant lungs with larger conducting airway volumes compared to C3 mice. Therefore to approach experimentally the epidemiological finding of higher susceptibility for respiratory diseases among individuals with lower basal pulmonary function we have selected JF1, a strain previously characterized for limited pulmonary function as the physiological base [16-18] and physically-chemically well characterized, endotoxin free moderately toxic carbon nanoparticles (Printex 90) as the toxicological base in this study $[19,20]$. Through this broad explorative study our prime aim was to identify the potentially important molecular events taking place during the acute inflammatory response and its resolution following CNP exposure in JF1 mice and to compare the response to that of recently assessed in C3 mice, a strain with higher basal pulmonary function [21].

\section{Methods}

The experiments were carried out using identical methodology as previously described by Ganguly et al [21].

\section{Particles}

For CNP instillation endotoxin free Printex 90 particles obtained from Degussa (Frankfurt, Germany) were used as described earlier [21]. The primary particle size of Printex 90 is $14 \mathrm{~nm}$, the specific surface area about $300 \mathrm{~m}^{2} / \mathrm{g}$, and the organic content low, 1-2\% [20]. Vials of $5 \mu \mathrm{g}, 20 \mu \mathrm{g}$ and $50 \mu \mathrm{g}$ CNP particles in $50 \mu \mathrm{l}$ were prepared just before use by suspending in pyrogen-free distilled water (Braun, Germany). The suspension of particles was sonicated on ice for $1 \mathrm{~min}$ prior to instillation, using a SonoPlus HD70 (Bachofer, Berlin, Germany) at a moderate energy of 20 Watt. We favor the use of distilled water for suspension of particles because the salt content of phosphate-buffered saline (PBS) causes rapid particle aggregation comparable to the "salting-out" effect and thus eliminates consistent instillation conditions. Particle characteristics have been described previously [21]. Briefly, The Zeta potential and intensity weighted median dynamic light scattering diameter of the printex 90 particles in a pyrogen free distilled water suspension at a concentration of $20 \mu \mathrm{g} / 50 \mu \mathrm{l}$ using Zetatrac (Model NPA151-31A; Particle Metrix GmbH, Meerbusch, Germany) was $33 \mathrm{mV}$ and $0.17 \mu \mathrm{m}$ respectively.

\section{Mouse procedures Animals}

This study was approved by the Bavarian Animal Research Authority (Reference No: 55.2-1-54-2531-115-05). Female JF1/Msf (JF1) animals were purchased from the Jackson Laboratories (Bar Harbour, ME USA) at the age of 8 weeks. The animals were housed and acclimatized at the animal facility of Helmholtz Zentrum München under specific pathogen free conditions according to the European Laboratory Animal Science Association Guidelines [22] for at least 4 weeks. Food and water were available $a d$ libitum. The experiments were performed with 12-14 weeks old animals. Mean body weight was $14.3 \pm 1.7 \mathrm{~g}$ (mean \pm SEM). Experimental groups were age matched and the age of 12-14 weeks was considered for this study so as to exclude the effect of any lung developmental events that may interfere with susceptibility. By the age of 
10 weeks lung development is completed in mice and the lung is fully grown and has a mature structure [23].

Mice were anesthetized by intraperitoneal injection of a mixture of xylazine $(4.1 \mathrm{mg} / \mathrm{kg}$ body weight) and ketamine (188.3 $\mathrm{mg} / \mathrm{kg}$ body weight). The animals were then intubated by a nonsurgical technique [24]. Using a bulbheaded cannula inserted $10 \mathrm{~mm}$ into the trachea, a suspension containing 5, 20, or $50 \mu \mathrm{g}$ CNP (Printex90) particles, respectively, in $50 \mu \mathrm{l}$ pyrogene-free distilled water was instilled, followed by $100 \mu \mathrm{l}$ air. Animals were treated humanely and with regard for alleviation of suffering.

\section{Experimental design}

Seven experimental groups were selected which included cage control, sham (vehicle) exposed, and CNP exposed (5 $\mu \mathrm{g} /$ day1, $20 \mu \mathrm{g} /$ day1, $20 \mu \mathrm{g} /$ day3, $20 \mu \mathrm{g} /$ day7, $50 \mu \mathrm{g} /$ day1) by intratracheal (i.t.) instillation. Cage control animals were not instilled, and sham animals received $50 \mu \mathrm{l}$ pure distilled water (vehicle). The animal groups were designed so as to obtain an acute dose-response relationship [ $5 \mu \mathrm{g} /$ day1, $20 \mu \mathrm{g} /$ day1 and $50 \mu \mathrm{g} /$ day1] and also to get a time course response [20 $\mu \mathrm{g} /$ day $1,20 \mu \mathrm{g} /$ day3, $20 \mu \mathrm{g} /$ day7] following i.t. instillation. Therefore 5 groups were exposed to particles and 2 groups served as control (cage control and sham exposed). Each of the seven experimental groups consisted of 11 animals (7 for lavage and 4 for histopathology) based on our previous experiences [21]. Out of the 7 lavaged animals, tissue samples from 4 mice were collected for protein analysis and 3 for future RNA studies. Four non-lavaged animals were used for histopathology. Lavaged lungs were immediately frozen in liquid nitrogen following dissection and stored at $-80^{\circ} \mathrm{C}$ until next procedures for molecular analysis.

\section{Bronchoalveolar lavage (BAL) and analysis}

On day1/day3/day7 (as per experimental design) after instillation, mice were anesthetized by intraperitoneal injection of a mixture of xylazine and ketamine and sacrificed by exsanguination. BAL was performed accordingly (i.e. day1/day3/day7 after instillation) by cannulating the trachea and infusing the lungs 10 times with $1.0 \mathrm{ml}$ PBS without calcium and magnesium, as described previously [21]. The BAL fluid from lavages 1 and 2 were pooled and centrifuged ( $425 \mathrm{~g}, 20 \mathrm{~min}$ at room temperature). The cellfree supernatant from lavages 1 and 2 were pooled and stored at $-20^{\circ} \mathrm{C}$ immediately for biochemical measurements such as total protein and panel assays. The cell pellet from lavages 1 and 2 was resuspended immediately in 1 mL RPMI 1640 medium (BioChrome, Berlin, Germany) and supplemented with $10 \%$ fetal calf serum (Seromed, Berlin, Germany); the number of living cells was determined by the trypan blue exclusion method. We performed cell differentials on the cytocentrifuge preparations (May-Grünwald- Giemsa staining; $2 \times 200$ cells counted). We used the number of polymorphonuclear leukocytes (PMNs) as a marker of inflammation. Total protein content was determined spectrophotometrically at $620 \mathrm{~nm}$, applying the Bio-Rad Protein Assay Dye Reagent (no. 500-0006; BioRad, Munich, Germany). We analyzed $50 \mu \mathrm{lBL} / \mathrm{mouse}$ for panel assays.

\section{Histology}

Four not lavaged animals per experimental group were used for histological analysis. Mice were sacrificed by an overdose of ketamin and the lungs were inflation-fixed at a pressure of $20 \mathrm{~cm} \mathrm{H}_{2} \mathrm{O}$ by instillation of phosphate buffered $4 \%$ formaldehyde. Three cross slices of the left lobe and 4 slices of each right lobe were systematically selected and embedded in paraffin, and $4 \mu \mathrm{m}$ thick sections were stained with hematoxylin and eosin. The sections were then studied by light microscopy.

\section{Protein panel assays}

In this study we analyzed the identical set of 62 protein markers as already introduced while studying CNP exposure in C3 mice [21]. A detailed list of each of the 62 markers, their gene symbol and associated gene ontology terms, least detectable dose (LDD) etc. is supplied in Additional File 1, Table S1. Our panel of markers are known to play important roles in the following key processes of lung tissue: i) Initiation and amplification of inflammation ii) Induction of $\mathrm{T}$-cell independent macrophage activation iii) Regulation of dendritic cell maturation and differentiation, and iv) Regulation of T-cell activation and differentiation as described by [25].

Total lung homogenate was prepared using $50 \mathrm{mM}$ Tris-HCL with $2 \mathrm{mM}$ EDTA, pH 7.4 as the lysis buffer $(1000 \mu \mathrm{l})$ from 4 animals/experimental group using the whole lung. Using the Rodent MAPTM version 2.0 of the Rules Based Medicine (Austin, Texas) a panel of mostly proinflammatory and inflammatory markers was analyzed from total lung homogenate and BAL. BAL and lung homogenates were always taken from the same animals to avoid any inter-animal variation. BAL of the 4 animals/ group was pooled for the measurement and only the markers equal to/above $(\geq)$ the sensitivity level were considered. BAL was pooled from 4 animals as our focus was on the lung homogenate considering BAL concentrations of proteins are often below LDD. Sensitivity level was the LDD as provided by Rules Based Medicine. We considered in pooled samples the markers below sensitivity levels to be not reliable due to lack of scope for reproducibility in multiple independent samples. However, in the lung homogenate markers below LDD were also considered for analysis and discussion as we could measure samples from 4 independent animals/group. In most cases little variance between replicates was observed.

Additionally three more markers hemoxygenase-1 (HO-1; Stressgen Catalog \# 960-071), osteopontin (SPP1; Stressgen Catalog \# 900-090A) and lipocallin-2 (LCN2; R\&D Systems Catalog \# DY1857) were assayed from the same samples using the respective ELISA kits. 


\section{Heatmaps and pathway analysis}

Protein expression data from lung tissue (means, $\mathrm{n}=4$ ) and BALF (pools from 4 animals) were used for heatmap generation. Protein concentrations were normalized to the highest value for each protein (set to equal 1) and the resulting values were used as input for heatmap generation with CARMAweb [26]. The Ingenuity Pathway Analysis tool was used to generate the interaction network for selected regulated proteins and to identify their biological functions.

\section{Statistics}

A two-way analysis of variance (ANOVA) was used to analyze differences between control and various exposure groups. P values less than 0.05 were considered as statistically significant. All computations were done by the software packages Statgraphics plus v5.0 (Manugistics, Rockville, MD) and SAS V9.1 (Cary, NC). All the data were normally distributed (F-test). Data are presented as arithmetic mean values of $n$ observations \pm the standard error (SE).

\section{Results}

The exposure groups were designed to assess an acute dose-response relationship one day after intratracheal instillation of $5 \mu \mathrm{g}(0.35 \mathrm{~g} / \mathrm{kg} \mathrm{BW}), 20 \mu \mathrm{g}(1.4 \mathrm{~g} / \mathrm{kg} \mathrm{BW})$ and $50 \mu \mathrm{g}$ Printex 90 (3.5 g/kg BW). The time course response was obtained for the moderate dose of $20 \mu \mathrm{g} / \mathrm{mouse}$ lung on day 1 , day 3 and day 7 . We have not observed any significant difference between cage control and sham exposed control animals in any of the measurements performed using BAL and lung homogenate.

\section{Dose and time response of BAL cells}

The total number of retrieved BAL leucocytes was not affected after i.t. instillation of $5 \mu \mathrm{g}$ CNP $(0.27 \pm 0.04 \times$ $10 \mathrm{E} 6$ cells/lung versus $0.27 \pm 0.05 \times 10 \mathrm{E} 6$ cells/lung in sham exposed mice) but increased two fold to $0.53 \pm$ $0.06 \times 10 \mathrm{E} 6$ cells/lung at day $1(\mathrm{p}<0.05)$ after instillation of $20 \mu \mathrm{g}$ CNP (data not shown). The time course analysis revealed an intermittent decline of BAL leucocytes almost to control level on day $3(0.31 \pm 0.07 \times 10 \mathrm{E} 6$ cells/lung, n.s.) followed by an increase to $0.51 \pm 0.11 \times 10 \mathrm{E} 6$ cells/ lung on day 7 , i.e. to $188 \%$ of that observed in sham exposed mice.

\section{PMN}

As observed for the total cell count no significant induction of PMN was detected following i.t instillation of $5 \mu \mathrm{g}$ CNP $(8.9 \pm 2.3 \times 10 \mathrm{E} 3 \mathrm{PMNs})$ compared to control $(9.7 \pm$ $1.5 \times 10 \mathrm{E} 3$ PMNs, Figure 1a). The increase of PMN numbers detected on day1 after $20 \mu \mathrm{g}$ or $50 \mu \mathrm{g}$ CNP instillation already reached saturation at the $20 \mu \mathrm{g}$ dosage. A 25-fold induction of PMN was detected following $20 \mu \mathrm{g}(246 \pm 58$ $\times 10 \mathrm{E} 3 \mathrm{PMNs})$ and a 19-fold after $50 \mu \mathrm{g}(182 \pm 31 \times 10 \mathrm{E} 3$ PMNs) CNP instillation. Time course analysis of PMN numbers revealed significantly reduced PMN counts after 3 days $(73.9 \pm 22.1 \times 10 \mathrm{E} 3 \mathrm{PMNs})$ and 7 days $(48.5 \pm 27.4$ $\times 10 \mathrm{E} 3 \mathrm{PMNs}$ ) compared to that of day1. However at day 3 and day 7 the PMN count remained 8 and 5 times higher $(<0.05)$, respectively, than the baseline values indicating incomplete resolution of the neutrophil influx related inflammation following $20 \mu \mathrm{g}$ of CNP instillation.

\section{Macrophages}

No dose dependent increase of macrophage numbers was observed (Figure 1b). Strikingly, in the time course analysis an obvious, 1.8-fold induction of macrophage numbers was detected at day $7(455 \pm 83 \times 10 \mathrm{E} 3$, vs. sham $257 \pm 48 \times 10 \mathrm{E} 3, \mathrm{p}<0.05)$.

\section{Lymphocytes}

The acute response of lymphocytes on day 1 is to some extent comparable to that of PMNs showing the highest influx with the $20 \mu \mathrm{g}$ but not at the $50 \mu \mathrm{g}$ dosage (Figure 1c). Strikingly, in the time course analysis a moderate induction of lymphocyte numbers in response to 20 $\mu \mathrm{g}$ CNP was detected on day 1 (4.9 times) and day3 (7.6 times) followed by a strong induction of lymphocyte numbers being detected on day 7 (35.1 times). It is interesting to note that the time course response of lymphocytes resembles that of the macrophages as both cell types show a maximum influx at day 7 .

\section{BAL protein concentration}

Compared to sham exposed mice, only the instillation of the highest dose $(50 \mu \mathrm{g} /$ mouse $)$ caused a significant (2.1 fold) increase in total BAL protein concentration (131.5 $\pm 14.5 \mu \mathrm{g} / \mathrm{ml}$ versus $280.1 \pm 8.3 \mu \mathrm{g} / \mathrm{ml}, \mathrm{p}<0.05) 1$ day after CNP instillation indicating alveolar barrier injury with capillary leakage only at this concentration (Figure 1d). Time course investigation of $20 \mu \mathrm{g}$ instilled lungs revealed no changes of BAL protein concentrations from day 1 to day 3 and day 7 .

\section{Histopathology}

Histopathological analysis of paraffin embedded JF1 lung sections $(n=4)$ showed a typical dose dependent accumulation of particle laden macrophages on days 1, 3 and 7 (Figure 2a-e). In $50 \mu \mathrm{g}$ /day 1 samples inflammatory cell infiltration (PMN) was clearly visible (Figure 2e) whereas at $20 \mu \mathrm{g} /$ dayl only slight PMN infiltration was detectable (data not shown).

\section{Molecular analysis for lung and BAL compartment}

In the present study a panel of 62 protein markers was applied to assess the CNP response in JF1 mice as 

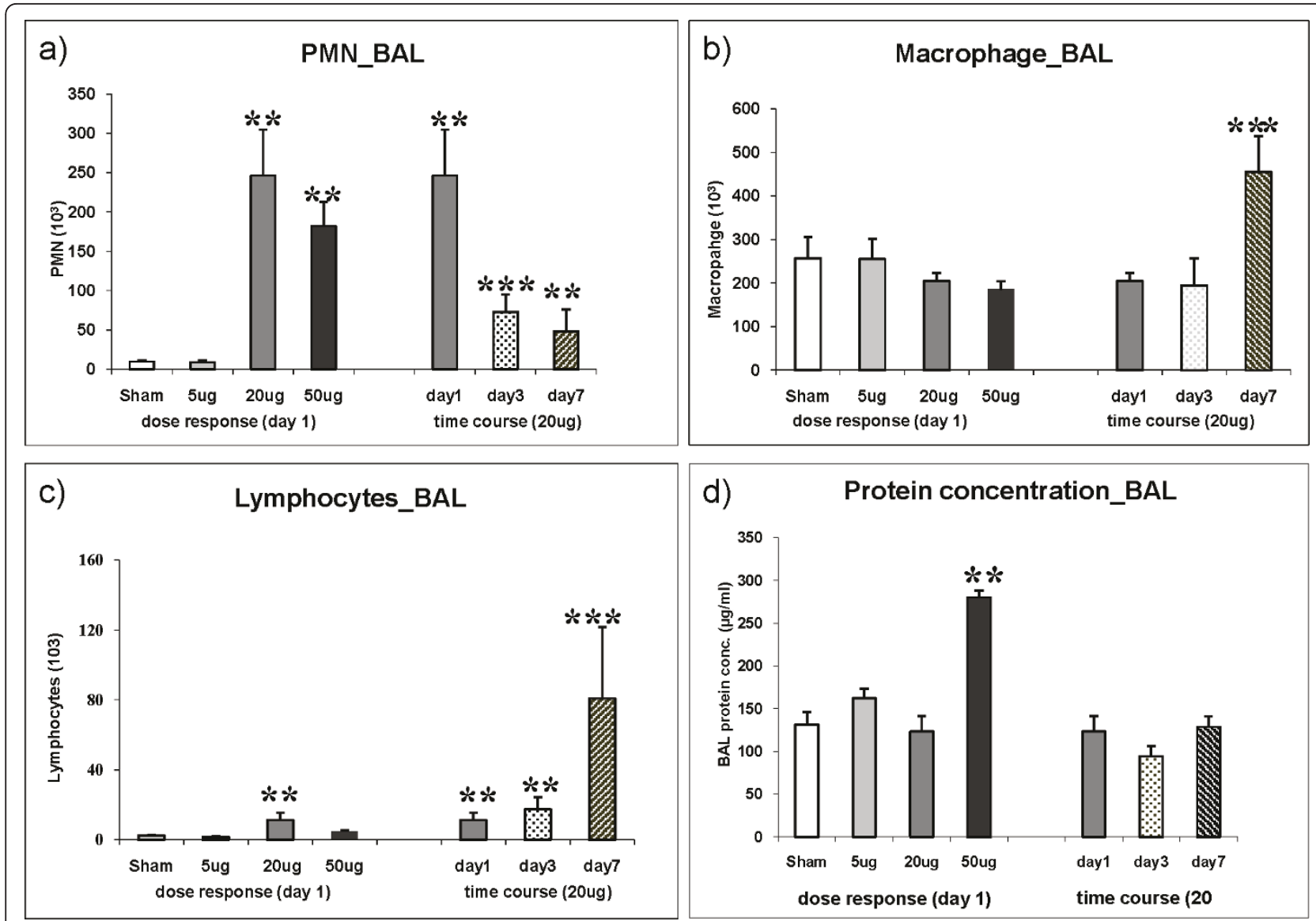

Figure 1 Bronchoalveolar lavage fluid (BAL) cell differentials and protein concentration. Dose dependent influx and time dependent resolution of (a) polymorphonuclear leukocytes (PMN), (b) macrophages, and (c) lymphocytes in the BAL following intratracheal (i.t.) instillation of carbon nanoparticles particles in the JF1/Msf (JF1) mice ( $n=7$ animals/experimental group). Total protein concentration is provided in Figure $1 \mathrm{~d}$. $\left(^{* *}\right)$ Significantly different with respect to (w.r.t) both sham control and $5 \mu \mathrm{g}$ exposed; ${ }^{* * *}$ ) significantly different w.r.t $20 \mu \mathrm{g}$ exposed at day1, sham control and $5 \mu \mathrm{g}$ exposed; $\mathrm{p} \leq 0.05$.

previously described for C3 mice [21]. A detailed list of each of the 62 markers is supplied in Additional File 1, Table S1.

\section{Lung compartment}

From the 62 markers 17 proteins did not exhibit any response in lung and were therefore not considered for analysis (CD40, CRP, EDN1, FGF9, F3, haptoglobin, IgA, IL17, IL2, SAP, SCF, SGOT, TF, HO-1, GST- $\alpha$, myoglobin, VCAM1). Dose and time course responses of the remaining 45 proteins are represented as a heat map in Figure 3. In the CNP dose response most proteins showed a strong upregulation already at a dose of $20 \mu \mathrm{g}$ and the expression level of 14 of them did not significantly increase further at a dose of $50 \mu \mathrm{g}$ (F7, FGA, GCP2/CXCL5, MCP1/CCL2, MCP3/CCL7, MCP5/CCL12, IP10/CXCL10, KC/CXCL1, MDC/ CCL22, MIP1b/CCL4, MIP2/CXCL2, MIP1g/CCL9, THPO and vWF). This observation can be associated with the dose response of PMN numbers in the BAL as these proteins include the major PMN recruiters CXCL1, 2, 5 and 10. From the 45 proteins 13 proteins were not significantly regulated at $20 \mu \mathrm{g} / \mathrm{day} 1$ but were significantly induced at $50 \mu \mathrm{g} /$ day1 (APOA1, CD 40L, EGF, FGF2, IFN-gamma, IL18, IL1B, IL3, IL4, IL5, MCSF/CSF1, MIP1 $\alpha / C C L 3$, and RANTES/CCL5).

For the time course study the majority of proteins exhibited the expected response pattern of initial increase (day1) and decline to baseline levels by day 7 following $20 \mu \mathrm{g}$ CNP exposure. Among them were: IL1B, MCP1/CCL2, MIP1/CCL4, MMP9, MCP3/CCL7, IP10/CXCL10, MPO, MIP2/CXCL2, IL6, GM-CSF/ CSF2, MIP1-gamma/CCL9, GCP-2/CXCL5, TIMP1, FGA, MCP-5/CCL12, KC/CXCL1. As evident from the list, the major PMN recruiters CXCL1, 2, 5 and 10 were down regulated at day 7 compared to day 1 reflecting the phenotypic observation of an obvious decline in PMN numbers until day 7 (Figure 3). 


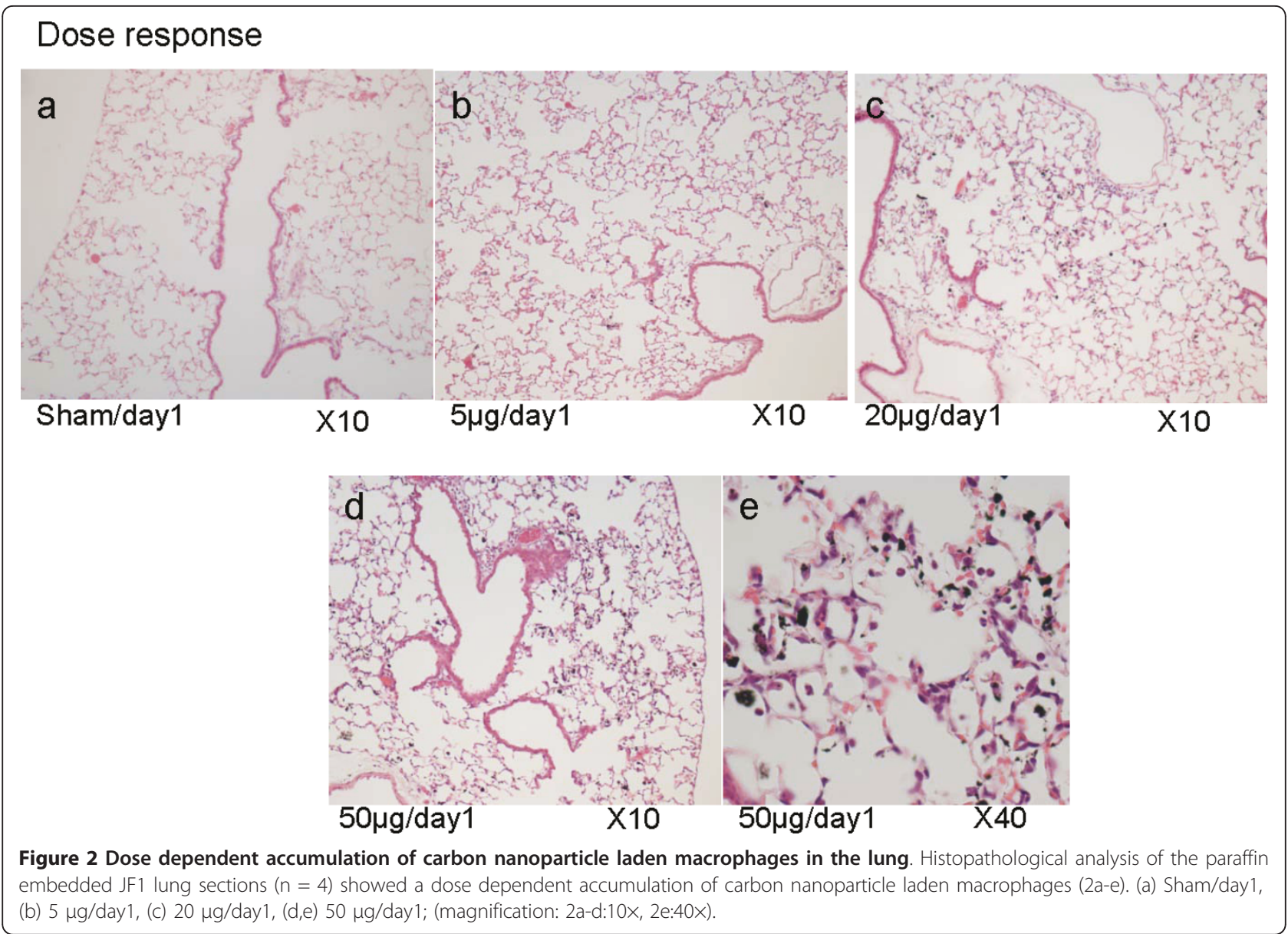

Further, we have detected 6 informative time course markers in the lung homogenate which showed an initial shoot up and remained at elevated levels until day 7 thereby correlating in particular with increased BAL cell differentials of alveolar macrophages and lymphocytes. These markers are IL1B, TNF, IL4, MDC/CCL22, F7, and vWF (all except vWF are at/above sensitivity level of detection). Their individual response pattern for the dose and the time response is shown in Figure 4. Interestingly IL4 in spite of not exhibiting an obvious dose response was detected at significantly higher levels at day 7 compared to sham, $5 \mu \mathrm{g}$ and $20 \mu \mathrm{g} /$ day 1 and day 3. A detailed list of each of the 62 markers is provided in Additional File 1, Table S1.

\section{BAL compartment}

For BAL, only markers detected at/above sensitivity level (see methods, $\mathrm{n}=4$ BAL samples were pooled/experimental group) were considered. This were 23 out of 62 markers as represented in the heatmap (Figure 3). With respect to the dose response, these 23 markers can be categorized in (i) BAL markers exhibiting increasing levels from $20 \mu \mathrm{g}$ to $50 \mu \mathrm{g}$ CNP/day1 being CCL22,
SPP1, CSF2, CXCL2, Lipocalin 2/LCN2, CCL2, CSF1, CCL7 and THPO; (ii) BAL markers exhibiting saturation at $20 \mu \mathrm{g} /$ day1, i.e. comparable levels at $20 \mu \mathrm{g}$ and $50 \mu \mathrm{g} /$ day1 being F3, IL1B, FGF2, F7, CCL3, CCL4, TNF, IL18, IL1A, VEGFA, and MMP9; and (iii) BAL markers (CXCL5, CCL9 and CD40L) exhibiting highest concentrations at $20 \mu \mathrm{g} /$ day1 and lower ones at $50 \mu \mathrm{g}$ dosage similar to lymphocyte numbers observed in BAL samples during the dose response study.

With respect to the time course, 19 of the $23 \mathrm{BAL}$ markers reached their baseline levels by day 7 in $20 \mu \mathrm{g}$ samples. Four markers - CCL22, CXCL5, CCL9 and MMP9 - exhibit a clear decline in concentration from day 1 to day7 but were somewhat elevated (1.5-2.5 fold higher) than baseline level on day 7 .

\section{Biological pathway analysis}

We identified 6 markers (IL1B, TNF, IL4, MDC/CCL22, F7, and vWF) which remained in elevated concentrations in the lung compartment (i.e. concentrations on day 7 were significantly higher to both sham and $5 \mu \mathrm{g}$ but not significantly lower to $20 \mu \mathrm{g} / 24 \mathrm{~h}$ or $20 \mu \mathrm{g} / 72 \mathrm{~h}$ ). This can be associated with the delayed macrophage- 


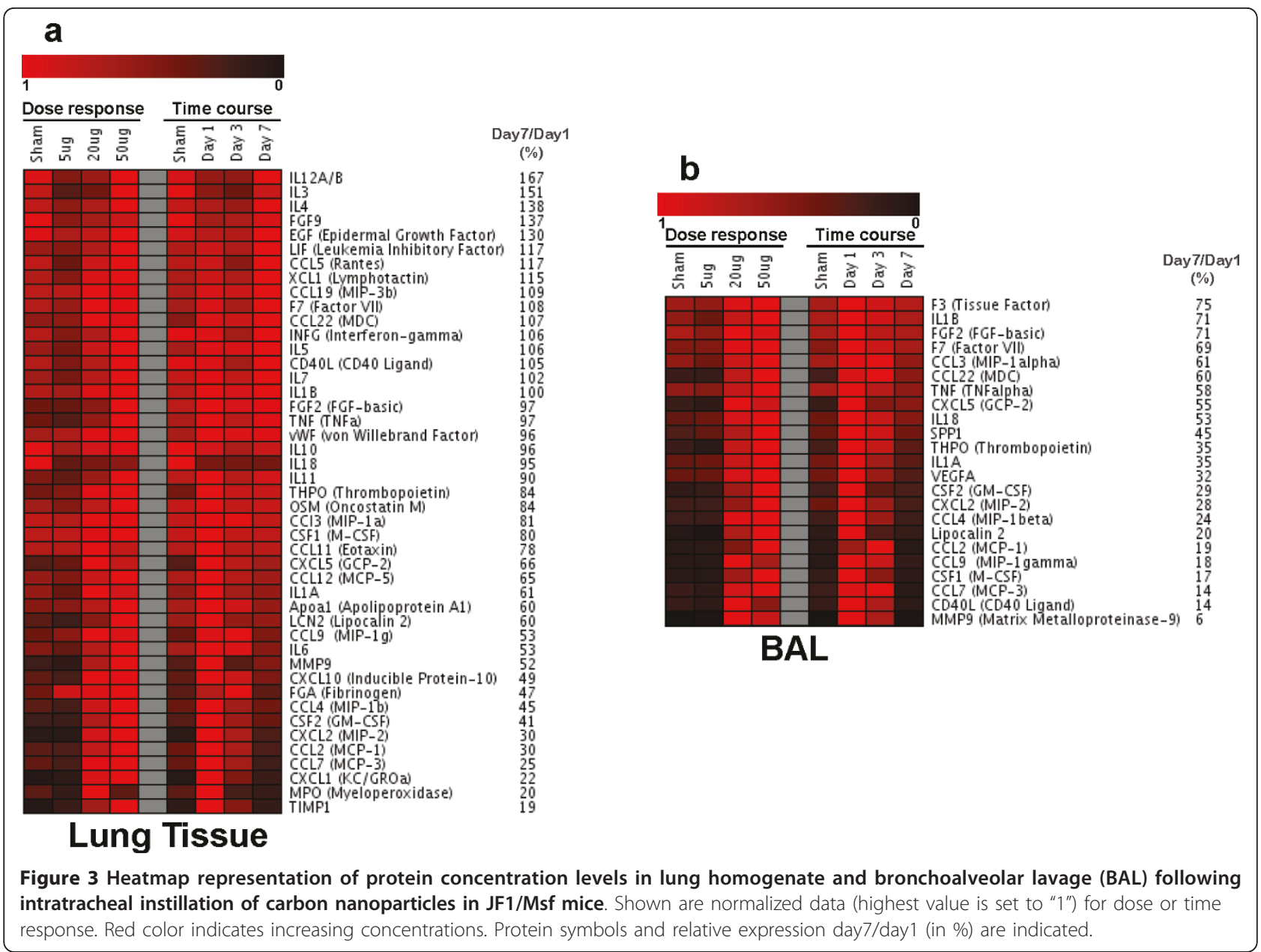

and lymphocyte influx. Based on these findings we performed an extensive literature study which revealed a close interaction between these markers which was also observed by an analysis with the Ingenuity pathway software. Known functions associated with the six marker proteins are airway inflammation, activation of macrophages and recruitment of lymphocytes (Figure 5).

\section{Discussion}

Previously we observed large variation in pulmonary function among inbred mouse strains $[17,18,27]$ and found that $\mathrm{C} 3 \mathrm{H} / \mathrm{HeJ}$ (C3) and JF1/Msf (JF1) to be the most divergent strains. In comparison to C3, JF1 mice have smaller, less compliant lungs with large conducting airway volumes and distinct morphological differences, like small alveolar dimensions. In JF1, total lung capacity (TLC, female) is $60 \%$ to that of $\mathrm{C} 3$, the static lung compliance is only less than half to that in $\mathrm{C} 3$, and the contribution of airway volume to TLC is 1.5 times more in JF1 than C3 [18]. The mean alveolar chord length is also smaller in JF1 compared to C3 [28]. Alveolar surface area being the site of immediate interaction is however similar among JF1 and C3 [28] (Table 1). Since lung size in mice shows only a moderate correlation to body weight [18] and the alveolar surface area does not differ among $\mathrm{C} 3$ and JF1 we decided to use the same CNP dosage for both strains to assess their acute inflammatory response and its resolution.

\section{Pulmonary response to CNP in JF1 mice}

The dose response of JF1 to CNP exposure was characterized by a marked PMN cell influx (up to 25 -fold induction) at day 1 reaching a saturation level already after instillation of $20 \mu \mathrm{g} C N P$ whereas at that time point no considerable macrophage recruitment into the alveolar space occurred. The marked influx of PMNs was associated with a number of elevated inflammatory cytokine levels, such as CXCL1, 2, 5, 10, CSF2, IL1B, CCL2, CCL7, TNF in lung tissue and partly also in BAL fluid (Figure 3). These cytokines are well known to be involved in PMN recruitment, [29]. Also extracellular matrix protecting proteins (TIMP1) and degrading enzymes (MMP9) were considerably induced. Typically, the acute inflammatory response to CNP is characterized by recruitment of PMN 


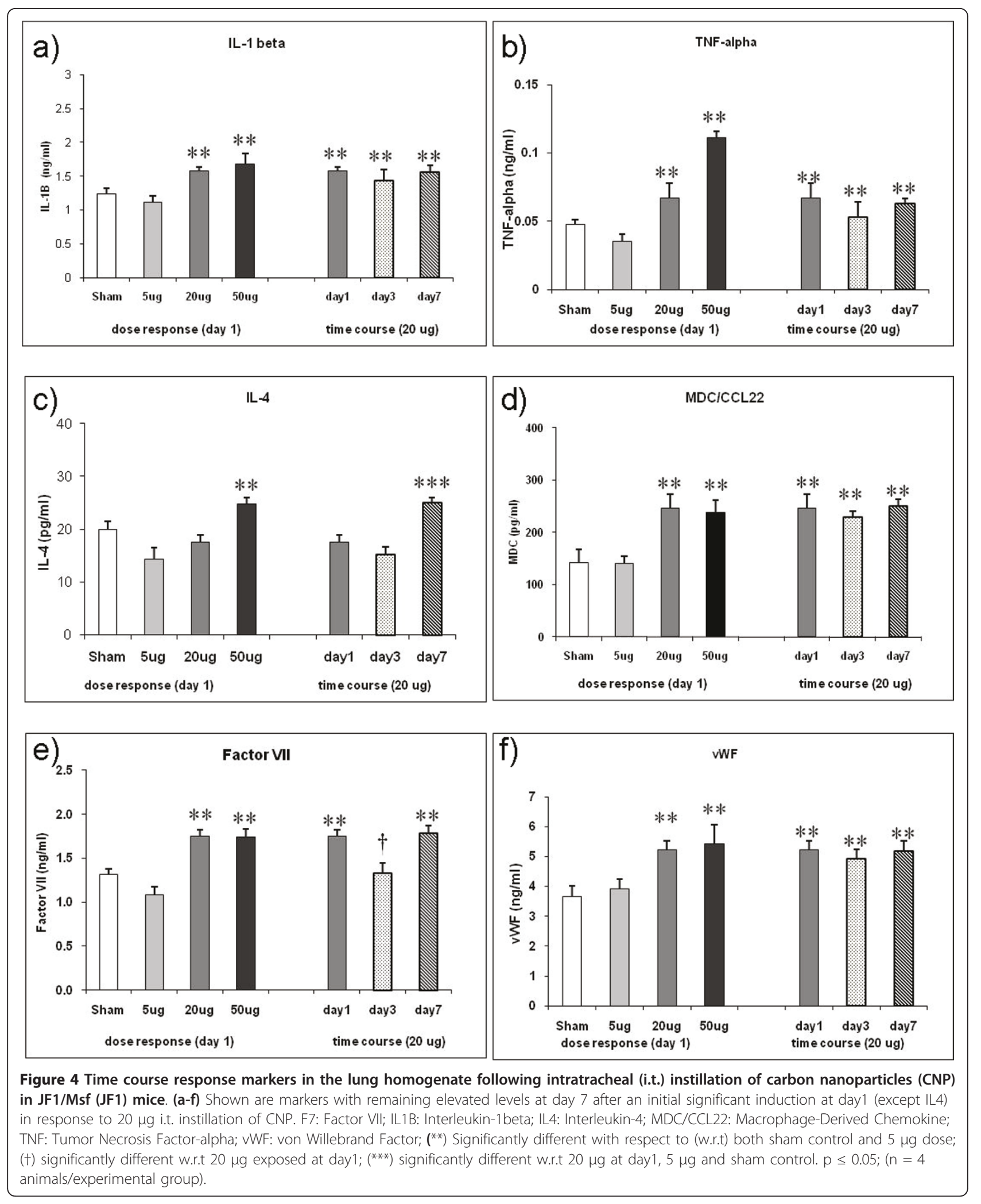




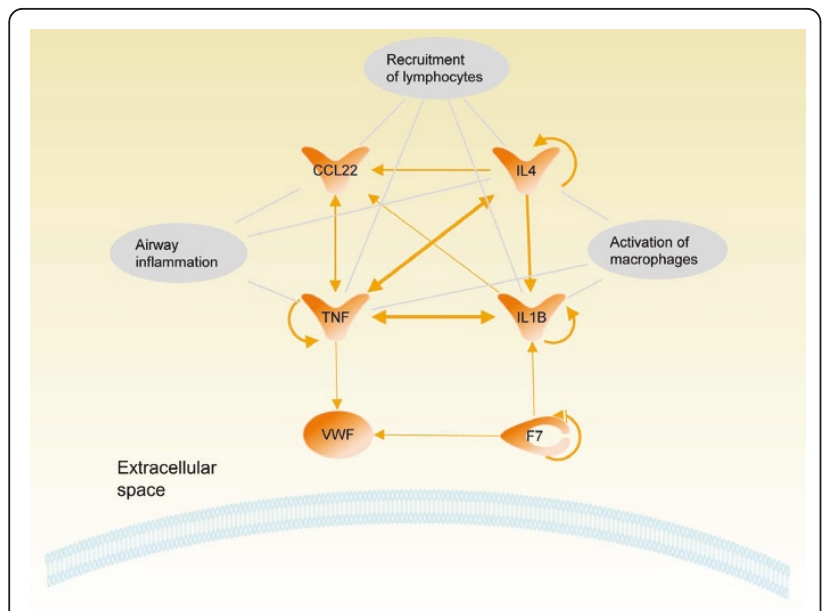

Figure 5 Pathway analysis of proteins detected at elevated concentrations during time course analysis in lung following intratracheal instillation of $20 \mu \mathrm{g}$ carbon nanoparticles (CNP). At day 7 when PMN levels were 5 times higher compared to baseline and a sudden influx of lymphocytes and macrophages was detected, Interleukin-1 beta (IL1B), Tumor necrosis factor-alpha (TNF), Factor VII (F7), Interleukin-4 (IL4), Macrophage-derived chemokine (MDC/CCL22) and von Willebrand Factor (VWF) remained at significantly elevated concentrations compared to their baseline levels. The predicted molecular network indicates the role of these markers in airway inflammation, recruitment of lymphocytes and activation of macrophages. Shown are the extracellular space, part of the cell membrane and published interactions are indicated by arrows (line thickness represents the number of references).

to the alveolar space with resolution and normalization of cell numbers after 3 to 7 days. However, detection of 5 times higher than baseline levels of PMN on day 7 after $\mathrm{CNP}$ exposure indicates that the ongoing resolution process is not complete at this time point in JF1 mice. The impaired resolution of inflammation is further supported by the delayed influx of macrophages (2-fold increased) and considerable recruitment of lymphocytes (35-times induced) into the airway lumen one week after treated with $20 \mu \mathrm{g}$ CNP. From the panel of protein markers analysed we have detected 6 markers - IL1B, IL4, MDC/ CCL22, TNF, F7, and vWF - which remained elevated up to day 7. Our pathway analysis revealed a close interaction

Table 1 Comparison of lung characteristics between female C3H/HeJ and JF1/Msf mice.

\begin{tabular}{llll}
\hline Parameter & C3H/HeJ & JF1/Msf & Reference \\
\hline Body weight $(\mathrm{g})$ & $22.4 \pm 0.6$ & $16.5 \pm 0.4$ & {$[18]$} \\
\hline Total Lung Capacity $(\mathrm{TLC})(\mu \mathrm{l})$ & $1443 \pm 29$ & $874 \pm 17$ & {$[17,18]$} \\
\hline $\begin{array}{l}\text { Static Lung Compliance }\left(\mathrm{s} \mathrm{C}_{\mathrm{L}}\right) \\
\left(\mathrm{cmH} \mathrm{H}_{2} \mathrm{O} / \mathrm{ml}\right)\end{array}$ & $84.8 \pm 3.6$ & $35.5 \pm 2.2$ & {$[17,18]$} \\
\hline Dead Space $\left(\mathrm{V}_{\mathrm{D}}\right)$ volume $(\%)$ & $15.8 \pm 0.3$ & $22.1 \pm 0.5$ & {$[17,18]$} \\
\hline Mean alveolar Chord length $(\mu \mathrm{m})$ & $69.2 \pm 14.8$ & $48.5 \pm 5.5$ & {$[28]$} \\
\hline Alveolar surface area $\left(\mathrm{cm}^{2}\right)$ & $847 \pm 70$ & $906 \pm 102$ & {$[28]$} \\
\hline
\end{tabular}

between these markers (Figure 5) and their implication in airway inflammation, activation of macrophages and recruitment of lymphocytes.

The proinflammatory markers TNF and IL1B remained elevated between day 1 and day 7. Elevated levels of IL1B and TNF in lung tissue are consistent with the observed impaired clearance of PMN from the lungs [30] resulting in the higher than baseline PMN levels on day 7. Due to their pleotrophic proinflammatory properties it is plausible that they are also involved in elevated numbers of alveolar macrophages detectable at day 7. In this context it is interesting to note that the cytokine IL4 exhibited increased levels either at high dosage ( $50 \mu \mathrm{g}$ CNP) on day 1 or at the $20 \mu \mathrm{g}$ dose on day 7. IL-4 is considered to be involved in chronic inflammatory responses [31] and is deeply involved in allergic airway inflammation, in regulation of lymphocyte differentiation of naïve helper T-cells to Th2 cells [32] as well as modulating the TNF mediated growth and differentiation of dendritic cells (DC) $[33,34]$. IL4 favors the polarisation of macrophages to the M2a type [31]. The macrophage derived chemokine CCL22 is a CC chemokine produced in a constitutive way by M2 macrophages [31], but also by dendritic cells (DC) and by activated B lymphocytes. CCL22 is chemotactic for DC, natural killer cells and activated $\mathrm{T}$ lymphocytes [35-37]. Taken together, our study shows that JF1 exhibit an impaired resolution of inflammation in response to CNP exposure. The delayed clearance of many pro-inflammatory cytokines which peaked at day 1 after CNP exposure together with still increased levels of IL1B, TNF, IL4, CCL22 could be associated with the delayed clearance of PMNs and increased numbers of macrophage and lymphocytes in the JF1 lungs detected one week after CNP exposure.

\section{Comparison of pulmonary responses to CNP in C3 and JF1 mice}

C3 mice were previously subjected to an identical exposure protocol as JF1 mice [21]. Although C3 mice showed a strong inflammatory response to CNP as evidenced by influx of PMNs into the alveolar space at the highest dose ( $\sim 40$ fold induction at $50 \mu \mathrm{g}$ CNP) and the induction of most of the biomarkers at day 1 (49 out of 62 were upregulated) they were able to completely resolve the PMN influx within 7 days. Moreover, in C3 mice cell numbers of macrophages and lymphocytes were not affected (Table 2). A defense/homeostasis pathway was activated, with IL1B/IL18, EDN1, FGF2, and VEGF [21] as the major players. Table 2 illustrates the distinct different responses to CNP in C3 and JF1 mice for BAL cells and selected biomarkers being either elevated at day 7 in C3 or JF1 mice. However, in response to CNP, many of the inflammatory biomarkers which were initially upregulated and remained elevated in C3 were not affected in 
Table 2 Time response in JF1 and C3 mice after single instillation of $20 \mu \mathrm{g}$ Printex 90: BAL cell differentials and protein markers expressed in lung tissue at day 1 and day 7

\begin{tabular}{|c|c|c|c|c|c|}
\hline & & \multicolumn{2}{|c|}{ JF1/Msf } & \multicolumn{2}{|c|}{$\mathrm{C} 3 \mathrm{H} / \mathrm{HeJ}$} \\
\hline & & Day1 & Day7 & Day1 & Day7 \\
\hline \multirow[t]{3}{*}{ BAL cell differentials } & PMN & $\uparrow$ & $\uparrow$ & $\uparrow$ & $\uparrow \leftrightarrow$ \\
\hline & Macrophages & NR & $\uparrow$ & $N R$ & $N R$ \\
\hline & Lymphocytes & NR & $\uparrow$ & $N R$ & NR \\
\hline \multirow[t]{23}{*}{ Lung tissue proteins } & IL1B & $\uparrow$ & $\uparrow$ & $\uparrow$ & $\uparrow$ \\
\hline & TNF & $\uparrow$ & $\uparrow$ & $\uparrow$ & $\leftrightarrow$ \\
\hline & IL4 & $\leftrightarrow$ & $\uparrow$ & $\uparrow$ & $\leftrightarrow$ \\
\hline & CCL22 & $\uparrow$ & $\uparrow$ & $\uparrow$ & $\leftrightarrow$ \\
\hline & F7 & $\uparrow$ & $\uparrow$ & $\uparrow$ & $\leftrightarrow$ \\
\hline & vWF & $\uparrow$ & $\uparrow$ & $\uparrow$ & $\uparrow$ \\
\hline & IL18 & $\downarrow$ & $\downarrow$ & $\uparrow$ & $\uparrow$ \\
\hline & VEGF & NR & NR & $\uparrow$ & $\uparrow$ \\
\hline & CSF1 & $\uparrow$ & $\leftrightarrow$ & $\uparrow$ & $\uparrow$ \\
\hline & CCL11 & $\uparrow$ & $\leftrightarrow$ & $\uparrow$ & $\uparrow$ \\
\hline & CCL5 & NR & NR & $\uparrow$ & $\uparrow$ \\
\hline & CCL9 & $\uparrow$ & $\leftrightarrow$ & $\uparrow$ & $\uparrow$ \\
\hline & CD40L & NR & NR & $\uparrow$ & $\uparrow$ \\
\hline & CCL4 & $\uparrow$ & $\leftrightarrow$ & $\uparrow$ & $\uparrow$ \\
\hline & $\mathrm{XCL1}$ & NR & $N R$ & $\uparrow$ & $\uparrow$ \\
\hline & CXCL5 & $\uparrow$ & $\uparrow \leftrightarrow$ & $\uparrow$ & $\uparrow$ \\
\hline & CCL3 & NR & NR & $\uparrow$ & $\uparrow$ \\
\hline & F3 & NR & NR & $\uparrow$ & $\uparrow \leftrightarrow$ \\
\hline & FGF2 & NR & NR & $\uparrow$ & $\uparrow$ \\
\hline & EDN1 & NR & NR & $\uparrow$ & $\uparrow$ \\
\hline & APCS & NR & NR & $\uparrow$ & $\uparrow$ \\
\hline & FGA & $\uparrow$ & $\leftrightarrow$ & $\uparrow$ & $\uparrow$ \\
\hline & THPO & $\uparrow$ & $\uparrow \leftrightarrow$ & $\uparrow$ & $\uparrow$ \\
\hline
\end{tabular}

$\uparrow:$ Higher than control; $\downarrow$ : Lower than control; $\leftrightarrow$ : Equivalent to control; $\uparrow \leftrightarrow:$ higher than control but lower than day 1; NR: no response; $(\mathrm{C} 3 \mathrm{H} / \mathrm{HeJ}$ data from reference 21)

JF1, like IL18, VEGF, CCL3, CCL5, Lymphotactin/XCL1, F3, EDN, CRP, APCS. On the other hand, in JF1 levels of TNF, IL4, CCL22, F7, vWF remained elevated at day7 which were though initially upregulated in C3 but most of them reached baseline levels at day 7. In particular, in JF1 mice elevated levels of IL1B and TNF were detected but not IL18 which was involved in the induction of EDN1/FGF2/VEGF homeostatic pathway in C3. This may in part explain the deleterious effects of CNP in JF1 mice. SOD3 is the main extracellular antioxidant enzyme of the lung. JF1 mice have 2-3 fold lower superoxide dismutase 3 (Sod3) transcript, protein and also activity levels in the lungs compared to C3 $[16,38]$. Interestingly, Laurila at al. [39] showed that SOD3 significantly reduces inflammatory cell migration of mononuclear cells after ischemic damage by regulating adhesion molecules and cytokine expression, among them TNF, which stayed elevated in JF1. Hence, it is reasonable to assume that depletion of SOD3 can alter the response to particle mediated oxidative stress. It may be plausible that the difference in the levels of superoxide dismutase 3 in the lungs of between C3 and JF1 influence the different response pattern to CNP.

\section{Conclusion}

JF1 exhibit an impaired resolution of inflammation in response to CNP exposure evidenced by a delayed clearance of PMNs from the lungs and an influx of mononulclear cells into the lungs one week after exposure. At the molecular level, this phenotype was associated with elevated levels of IL1B, TNF, IL4, CCL22, and the lack of establishing the defense/homeostasis pathway as recently proposed for $\mathrm{C} 3$ mice [21] which involves the upregulation of IL18, EDN1, FGF2, and VEGF. This suggests an increased susceptibility of JF1 to extrinsic insults and a potential disposition to continuing of inflammatory processes. Therefore these explorative studies identified plausible molecular pathways causing the different response to CNP in JF1 and C3 mice. Further pathway directed investigations are required to improve our understanding on the genetic and molecular basis of CNP induced inflammatory response.

\section{Additional material}

Additional file 1: Table S1. List of all analyzed proteins, their respective gene symbols, Entrez identification numbers, associated gene ontology terms according to the Mouse Genome Informatics (MGl) database, least detectable doses (LDD), and expression levels in BAL and lung.

\section{Acknowledgements}

The authors sincerely acknowledge the expert technical assistance received from Martina Schreiber, Birgit Frankenberger, Baerbel Ritter, and Maria Neuner. This work have been supported by grants from the National Institutes of Health (HL070542 to Dr Schulz; German Ministry of education and research (BMBF)/National Genome Research Network (NGFN) research grant 01 GS0120 to Dr Hamelmann, NGFNplus grant 01GS0850 to Dr. Beckers and NGFN grants 1GR0430, 01GSand 0120, 01GS0850 to Dr Schulz.

\section{Author details}

${ }^{1}$ Comprehensive Pneumology Center, Institute of Lung Biology and Disease, Helmholtz Zentrum München, German Research Center for Environmental Health, Neuherberg/Munich, Germany. ${ }^{2}$ Institute of Experimental Genetics, Helmholtz Zentrum München, German Research Center for Environmental Health, Neuherberg/Munich, Germany. ${ }^{3}$ Center of Life and Food Sciences, Technical University Munich, Freising, Germany. ${ }^{4}$ Department of Pediatric Pneumology and Immunology, Charité Universitätsmedizin Berlin, Berlin, Germany. ${ }^{5}$ Department of Pediatrics, Ruhr-University Bochum, Bochum, Germany. ${ }^{6}$ Department of Environmental and Occupational Health, University of Pittsburgh, Pittsburgh, PA, USA. Institute of Epidemiology, Helmholtz Zentrum München, German Research Center for Environmental Health, Neuherberg/Munich, Germany. 


\section{Authors' contributions}

$\mathrm{KG}, \mathrm{SU}, \mathrm{EH}, \mathrm{HS}$ and TS conceived and designed the experiments. KG, SU, ST, KP performed the experiment; KG, SU, ST, MI, JB, HS and TS analyzed the data; KG, SU, MI, MHA, TS and HS wrote the manuscript. All authors read and approved the final manuscript. Drs. Schulz and Stoeger contributed equally to this article

\section{Competing interests}

The authors declare that they have no competing interests.

Received: 7 May 2011 Accepted: 15 July 2011 Published: 15 July 2011

\section{References}

1. Bateson TF, Schwartz J: Selection bias and confounding in case-crossover analyses of environmental time-series data. Epidemiology 2001, 12(6):654-661.

2. Pope CA, Hansen ML, Long RW, Nielsen KR, Eatough NL, Wilson WE, Eatough DJ: Ambient particulate air pollution, heart rate variability, and blood markers of inflammation in a panel of elderly subjects. Environmental Health Perspectives 2004, 112(3):339-345.

3. Pope CA, Muhlestein JB, May HT, Renlund DG, Anderson JL, Horne BD: Ischemic heart disease events triggered by short-term exposure to fine particulate air pollution. Circulation 2006, 114(23):2443-2448.

4. Burrows B, Knudson RJ, Lebowitz MD: The relationship of childhood respiratory illness to adult obstructive airway disease. Am Rev Respir Dis $1977,115(5): 751-60$

5. Samet JM, Tager IB, Speizer FE: The relationship between respiratory illness in childhood and chronic air-flow obstruction in adulthood. Am Rev Respir Dis 1983, 127(4):508-23.

6. Stern DA, Morgan WJ, Wright AL, Guerra S, Martinez FD: Poor airway function in early infancy and lung function by age 22 years: a nonselective longitudinal cohort study. Lancet 2007, 370(9589):758-764.

7. Jacobsen NR, Moller P, Jensen KA, Vogel U, Ladefoged O, Loft S, Wallin H: Lung inflammation and genotoxicity following pulmonary exposure to nanoparticles in ApoE-/- mice. Part Fibre Toxicol 2009, 6:2.

8. BéruBé K, Balharry D, Sexton K, Koshy L, Jones T: Combustion-derived nanoparticles: mechanisms of pulmonary toxicity. Clin Exp Pharmacol Physiol 2007, 34(10):1044-50.

9. Stoeger T, Takenaka S, Frankenberger B, Ritter B, Karg E, Maier K, Schulz H, Schmid O: Deducing in vivo toxicity of combustion-derived nanoparticles from a cell-free oxidative potency assay and metabolic activation of organic compounds. Environ Health Perspect 2009, 117:54-60.

10. Su DS, Jentoft RE, Muller JO, Rothe D, Jacob E, Simpson CD, Tomovic Z, Mullen K, Messerer A, Poschl U, Niessner R, Schlogl R: Microstructure and oxidation behaviour of Euro IV diesel engine soot: a comparative study with synthetic model soot substances. Catalysis Today 2004, 90(suppl 1):127-132.

11. Raherison C, Girodet PO: Epidemiology of COPD. Eur Respir Rev 2009, 18(114):213-21.

12. Salvi SS, Barnes PJ: Chronic obstructive pulmonary disease in nonsmokers. Lancet 2009, 374(9691):733-43.

13. Oberdorster G, Oberdorster $E$, Oberdorster J: Nanotoxicology: an emerging discipline evolving from studies of ultrafine particles. Environ Health Perspect 2005, 113(7):823-39.

14. Nel A, Xia T, Madler L, Li N: Toxic potential of materials at the nanolevel. Science 2006, 311(5761):622-7.

15. Nel AE, Madler L, Velegol D, Xia T, Hoek EM, Somasundaran P, Klaessig F, Castranova V, Thompson M: Understanding biophysicochemical interactions at the nano-bio interface. Nat Mater 2009, 8(7):543-57.

16. Ganguly K, Stoeger T, Wesselkamper SC, Reinhard C, Sartor MA, Medvedovic M, Tomlinson CR, Bolle I, Mason JM, Leikauf GD, Schulz H: Candidate genes controlling pulmonary function in mice: transcript profiling and predicted protein structure. Physiol Genomics 2007, 31(3):410-21

17. Reinhard C, Eder G, Fuchs H, Ziesenis A, Heyder J, Schulz H: Inbred strain variation in lung function. Mamm Genome 2002, 13(8):429-37.

18. Reinhard C, Meyer B, Fuchs H, Stoeger T, Eder G, Ruschendorf F, Heyder J, Nurnberg $P$, de Angelis $M H$, Schulz H: Genomewide linkage analysis identifies novel genetic Loci for lung function in mice. Am J Respir Crit Care Med 2005, 171(8):880-8.
19. Matuschek G, Karg E, Schroppel A, Schulz H, Schmid O: Chemical investigation of eight different types of carbonaceous particles using thermoanalytical techniques. Environ Sci Technol 2007, 41(24):8406-11.

20. Stoeger T, Reinhard C, Takenaka S, Schroeppel A, Karg E, Ritter B, Heyder J, Schulz H: Instillation of six different ultrafine carbon particles indicates a surface area threshold dose for acute lung inflammation in mice. Environ Health Perspect 2006, 114(3):328-33.

21. Ganguly K, Upadhyay S, Irmler M, Takenaka S, Pukelsheim K, Beckers J, Hamelmann E, Schulz H, Stoeger T: Pathway focused protein profiling indicates differential function for IL-1B, -18 and VEGF during initiation and resolution of lung inflammation evoked by carbon nanoparticle exposure in mice. Part Fibre Toxicol 2009, 631

22. Nicklas W, Baneux P, Boot R, Decelle T, Deeny AA, Fumanelli M, lllgenWilcke B: Recommendations for the health monitoring of rodent and rabbit colonies in breeding and experimental units. Lab Anim 2002, 36(1):20-42.

23. Soutiere SE, Mitzner W: Comparison of postnatal lung growth and development between C3H/HeJ and C57BL/6J mice. J Appl Physiol 2006, 100(5):1577-83.

24. Brown RH, Walters DM, Greenberg RS, Mitzner W: A method of endotracheal intubation and pulmonary functional assessment for repeated studies in mice. J Appl Physiol 1999, 87:2362-2365.

25. Toews GB: Cytokines and the lung. Eur Respir J Suppl 2001, 343s-17s.

26. Rainer J, Sanchez-Cabo F, Stocker G, Sturn A, Trajanoski Z: CARMAweb: comprehensive R- and bioconductor-based web service for microarray data analysis. Nucleic Acids Res 2006, 34 Web Server: W498-503.

27. Schulz H, Johner C, Eder G, Ziesenis A, Reitmeier P, Heyder J, Balling R Respiratory mechanics in mice: strain and sex specific differences. Acta Physiol Scand 2002, 174(4):367-75.

28. Hühn D: Stamm- und geschlechtsspezifische Unterschiede der Lungenarchitektur sowie der Ultrastruktur der Alveolarsepten bei $\mathrm{C3H} /$ HeJ- und JF1/Msf-Mäusen. Philipps-Universität Marburg, Gießen; 2008, 107.

29. Feghali CA, Wright TM: Cytokines in acute and chronic inflammation. Front Biosci 1997, 2d12-26.

30. Larrick JW, Kunkel SL: The role of tumor necrosis factor and interleukin 1 in the immunoinflammatory response. Pharm Res 1988, 5(3):129-39.

31. Mantovani A, Sica A, Sozzani S, Allavena P, Vecchi A, Locati M: The chemokine system in diverse forms of macrophage activation and polarization. Trends Immunol 2004, 25(12):677-86.

32. Yamaji-Kegan K, Su Q, Angelini DJ, Johns RA: IL-4 is proangiogenic in the lung under hypoxic conditions. J Immunol 2009, 182(9):5469-76.

33. Cella M, Engering A, Pinet V, Pieters J, Lanzavecchia A: Inflammatory stimuli induce accumulation of MHC class II complexes on dendritic cells. Nature 1997, 388(6644):782-7.

34. Salomon B, Cohen JL, Masurier C, Klatzmann D: Three populations of mouse lymph node dendritic cells with different origins and dynamics. $J$ Immunol 1998, 160(2):708-17.

35. Godiska R, Chantry D, Raport CJ, Sozzani S, Allavena P, Leviten D, Mantovani A, Gray PW: Human macrophage-derived chemokine (MDC), a novel chemoattractant for monocytes, monocyte-derived dendritic cells, and natural killer cells. J Exp Med 1997, 185(9):1595-604.

36. Schaniel C, Rolink AG, Melchers F: Attractions and migrations of lymphoid cells in the organization of humoral immune responses. Adv Immunol 2001, 78111-68.

37. Tsai YC, Chang HW, Chang TT, Lee MS, Chu YT, Hung CH: Effects of alltrans retinoic acid on Th1- and Th2-related chemokines production in monocytes. Inflammation 2008, 31(6):428-33.

38. Ganguly K, Depner M, Fattman C, Bein K, Oury TD, Wesselkamper SC, Borchers MT, Schreiber M, Gao F, von Mutius E, Kabesch M, Leikauf GD, Schulz H: Superoxide dismutase 3, extracellular (SOD3) variants and lung function. Physiol Genomics 2009, 37(3):260-7.

39. Laurila JP, Laatikainen LE, Castellone MD, Laukkanen MO: SOD3 reduces inflammatory cell migration by regulating adhesion molecule and cytokine expression. PLoS One 2009, 4(6).

doi:10.1186/1465-9921-12-94

Cite this article as: Ganguly et al.: Impaired resolution of inflammatory response in the lungs of JF1/Msf mice following carbon nanoparticle instillation. Respiratory Research 2011 12:94. 